\title{
1 The remarkable reproductive diversity of teleost fishes
}

2 Carl Smith ${ }^{1} \&$ Robert J. Wootton ${ }^{2 *}$

$3{ }^{1}$ School of Biology, University of St. Andrews, St. Andrews, Fife, KY16 8LB, UK; Institute

4 of Vertebrate Biology, Academy of Sciences of the Czech Republic, Květná 8, 60365

5 Brno, Czech Republic

$6{ }^{2}$ Institute of Biological, Environmental and Rural Sciences, Aberystwyth University,

7 Aberystwyth, Ceredigion SY23 3DA, UK

$8 \quad{ }^{*}$ Author deceased

9 Correspondence: $\operatorname{Dr}$ Carl Smith, School of Biology, University of St Andrews, St

10 Andrews, Fife KY16 8LB, UK (email: cs101@st-andrews.ac.uk; tel: 01334 463448) 


\section{Abstract}

12 Teleosts display the most striking reproductive diversity of all vertebrates. However, no

13 convincing hypothesis has yet been proposed to explain why they have evolved this

14 remarkable variability in their modes of reproduction. Some of the features of the

15 reproductive biology of teleosts are briefly reviewed and unique characteristics of the

16 group that may have made possible the evolution of their remarkable reproductive

17 diversity are considered. These include whole genome duplication, the mode of

18 differentiation of the gonads, and the organisation of the brain-pituitary relationship.

19 Keywords: alternative mating tactics, hermaphroditism, mating system, self-fertilisation,

20 sex determination, unisexuality, viviparity

21 Running title: Reproductive diversity of teleosts 


\section{Introduction}

23 Teleost fishes are an evolutionary puzzle. They display virtually every mode of 24 reproduction found in vertebrates (Desjardins and Fernald 2009). Yet why this group 25 has evolved such exuberant variation in its reproduction has still to be convincingly 26 explained (Wootton and Smith 2015). In this brief review I summarise some of the

27 features of the reproductive biology of teleosts and suggest unique characteristics of the 28 group that may have made possible the evolution of this remarkable reproductive 29 diversity.

\section{Modes of reproduction in teleosts}

\section{Gender systems}

32 In terms of sex determination, about $88 \%$ of known teleosts are gonochorists, with 33 individuals either male or female (Patzner 2008). Gonochorism is the usual condition in 34 vertebrates. The sex of an individual can be determined genetically, known as genetic 35 sex determination (GSD). Sex can also be determined by the environmental conditions encountered in the early stages of development of the individual; termed environmental sex determination (ESD). Sex in some teleosts is determined by interactions between genes and the environment. Functional hermaphroditism, which is extremely rare in other vertebrate groups, has been identified in about $2 \%$ of teleost species, representing approximately 30 families. Its taxonomic distribution in the teleosts suggests hermaphroditism has evolved independently in several teleost lineages (Patzner 2008;

42 Avise and Mank 2009; Erisman et al. 2013). Interestingly, in some gonochoristic teleost species, the gonad initially differentiates as an ovary even in individuals that eventually

44 become male and there seems to be indeterminacy in the teleostean gonad in relation to 45 development as an ovary or testis, which predisposes them towards hermaphroditism. 46 Hermaphroditism in the teleosts can be simultaneous (synchronous) or sequential, the 
47 latter mode expressed as protandrous, protogynous or serial (bi-directional)

48 hermaphroditism (Avise and Mank 2009). The commonest forms of hermaphroditism 49 are protandry and protogyny. In simultaneous hermaphroditism, the gonads contain 50 both male (spermatozoa) and female (eggs) haploid gametes at the same time. The co51 occurrence of spermatozoa and eggs opens up the possibility of self-fertilisation by an 52 individual, but this has been described for only two closely related species, the 53 cyprinodont mangrove rivulus (Kryptolebias marmoratus and $K$. hermaphroditus, 54 Rivulidae) (Tatarenkov et al. 2012). Other species with simultaneous hermaphroditism 55 outcross, mating with other individuals. Protandry describes the situation in which an individual functions as a sexually mature male, producing spermatozoa, but at some 57 point in its life history switches to perform as a female, spawning eggs. Protogyny is the reverse of this. When sexually mature, an individual is initially female, spawning eggs,

59 but then later transforms into a male producing spermatozoa. In serial species, the switch between male and female roles can take place more than once in a lifetime. Parthenogenesis, in which only the female genome is transmitted from 62 generation to generation, also occurs in the teleosts, although it is rare. A curious feature of parthenogenesis in most teleost biotypes that exhibit this mode of reproduction, such as the Amazon molly (Poecilia formosa), is that they require the presence of males from 65 a closely related gonochoristic species (Lampert and Schartl 2008; Pandian 2011; 66 Wootton and Smith 2015). The male spermatozoon activates the development of the egg 67 of the parthenogenetic female. Teleosts show two modified forms of parthenogenesis: 68 gynogenesis and hybridogenesis. In hybridogenesis, the genetic material of the male is 69 functional in the developing individual, but when that individual reproduces only the 70 female genome is transmitted to the progeny. In gynogenesis, the role of the 71 spermatozoon is solely to activate the egg and the genes of the male play no role in the 72 development of the zygote (Wootton and Smith 2015). Thus, parthenogenetic females 
essentially parasitise the spermatozoa of the gonochoristic males (Neaves and Baumann

74 2011).

\section{Spawning dynamics}

76 There are two major temporal patterns of reproductive activity that can be recognised 77 in the life history of teleosts (Stearns 1992; Wootton 1998; Roff 2002). Semelparity 78 describes the condition in which, after attaining sexual maturity, the individual breeds 79 once and then dies without significant post-reproductive survival. In semelparous 80 organisms, the physiological changes associated with reproduction result in 81 consequences that inevitably end in death. Iteroparity is the condition in which, after reproduction, there is some probability that the individual will survive to breed again. In this case, reproduction typically takes place at yearly intervals.

Within a breeding season, two temporal patterns of spawning occur in female teleosts (Wootton 1998; Patzner 2008). In total spawners, the female spawns all her eggs over a short period of time and no further eggs are shed in that breeding season. If the female is semelparous, she then dies. If iteroparous, her ovaries regress and become quiescent until the physiological and environmental conditions induce the

89 recrudescence of the ovaries leading to the production of eggs for the next breeding season. In batch spawners, the female spawns eggs in batches (or clutches) at intervals

91 during the breeding season, which is typically of an extended duration. The interval

92 between spawnings varies. In some species, the female may spawn at daily intervals, but

93 in others, spawning takes place at intervals of several days. There are two types of batch

94 spawner. Some species have determinate fecundity. The females have all the eggs that 95 are going to be spawned during that breeding season present in the ovaries at the start 96 of the breeding season and there is no addition to the pool of eggs available to be 
spawned in that season. Other species have indeterminate fecundity. Here, the pool of eggs that can be spawned can be replenished during the breeding season.

In short-lived fishes, the females may be batch spawners, but may not survive to breed in the next breeding season. They thus share the characteristics of semelparous and iteroparous species. However, in such species, there is usually the physiological capacity to survive to the next breeding season if environmental conditions are benign. Such species can be described as showing abbreviated iteroparity.

\section{Modes of fertilisation}

The vast majority of teleost species have external fertilisation (Patzner 2008). The eggs and sperm are released into water, where fertilisation takes place. In about 500-600 species, fertilisation takes place internally within the female. The male introduces the spermatozoa into the gonoduct of the female, using an intromittent organ (Wourms 1981). This is analogous to the mode of fertilisation seen in the cartilaginous fishes, the Chondrichthyes, and in mammals and a few other vertebrates. In most teleosts with internal fertilisation some development of the fertilised egg takes place within the ovary of the female, but in a few species the eggs are deposited soon after fertilisation. In some cichlid species in which the female broods the fertilised eggs in her buccal cavity, the female lays the eggs and then sucks them into her buccal cavity and also sucks in the male's spermatozoa, so the eggs are fertilised within the buccal cavity (Fryer and Iles 1972).

\section{Mating systems}

Teleosts also show diversity in the social contexts in which mating occurs (Patzner 2008; Wootton and Smith 2015). These contexts differ in the extent to which they allow some selection of partners by the mating fish. In promiscuity, males potentially fertilise the eggs of several females and the eggs of a female may be fertilised by several males, 
122 with minimal selection of partners. Polygamy refers to the social situation in which an

123 individual mates with several partners, but with the possibility of some selection of the

124 partner at each spawning. Males in polygynous species mate with several females, but

125 each female spawns only with one male. Females in polyandrous species mate with

126 several males, but each male spawns with only a single female. In this system the male

127 may assume the parental role. A form of promiscuity, but with the possibility of mate

128 selection, is polygynandry. A male will spawn with several females and a female with

129 several males over the course of a breeding season, but with mate choice operating. In

130 monogamy, a single male and female form a mating pair and show some degree of

131 bonding with the mate. This type of mating system is particularly associated with

132 species in which parental care follows the fertilisation of eggs. The pair bond may be

133 long lasting or more temporary, only persisting for a single breeding attempt. Even in

134 socially monogamous systems, both males and females may take part in extra-pair 135 spawnings, so socially monogamous matings systems may not be genetically 136 monogamous (Wootton and Smith 2015).

137 Where a pair bond forms, if only for as long as it takes for successful spawning, 138 the bond may be subverted by other males, who take advantage of the pairing to steal or

139 'sneak' fertilisations by depositing sperm close to, or at, the site of spawning. The 140 sneaking males are demonstrating an alternative mating tactic (Taborsky 2008).

\section{Secondary sexual characteristics}

142 Sexually mature males and females may differ in appearance, either permanently or only

143 in the breeding season (Helfman et al. 2009; Wootton and Smith 2015). In sexually 144 monomorphic species, there are no obvious differences between sexually mature males 145 and females, although one or both sexes may produce pheromones to attract mates. The 146 sexual dimorphism may only be present during the breeding season and outside of 
147 breeding, males and females are indistinguishable. However, in some species, the sexual

148 dimorphism is permanent, so sexually mature males and females can be reliably 149 identified (Pandian 2011).

\section{Parental care}

151 The majority of teleost species show no post-fertilisation care of their progeny.

152 However, in a number of teleost lineages, parental care has evolved, taking different 153 forms in different lineages (Mank et al. 2005). The commonest form is paternal care, in 154 which the male cares for one of more clutches of fertilised eggs. An extreme form of this 155 is seen in the pipefishes and seahorses (Syngnathidae). The female transfers eggs to a 156 brood pouch on the abdomen of her male partner and the eggs develop in the male's 157 pouch in a form of male pregnancy (Kolm 2009).

In maternal care, the female takes care of the developing eggs. The nature of the

159 maternal care depends on the mode of fertilisation. If the eggs were fertilised externally, 160 the female must protect the eggs from adverse environmental conditions. Incubation in 161 the buccal cavity is one solution to this problem. The female scoops up the eggs in her 162 mouth and the eggs complete their development in their mother's buccal cavity (Kolm 163 2009). A second form of maternal care is seen in viviparous species in which the eggs 164 are fertilised and develop in the ovaries of the female. In some viviparous species, the 165 female provides only protection, but in others provides the developing eggs with 166 nutrients in a way analogous to pregnancy in mammals (Wourms 1981).

167 In a few species with external fertilisation, there is bi-parental care, with the 168 female and male co-operating in care of the young. In this situation, the female and male 169 may show some division of labour, often with the male protecting the area around the 170 eggs and the female tending to the eggs and young stages (Smith and Wootton 1995). An 171 even rarer form of parental care has been described for a few cichlid species. The 
172 parents are helped in the care of a current brood by juveniles from a previous spawning.

173 This phenomenon of juvenile helpers has been well studied in birds, but less so in

174 teleosts (Wong and Balshine 2011).

\section{Unique characteristics of teleosts}

\section{Species number}

177 In terms of number of species, teleosts are by far the most speciose of the vertebrates, 178 with about 30,000 species, representing approximately half of all vertebrates (Helfman 179 et al. 2009). Associated with this diversity is the extremely wide range of aquatic 180 habitats that teleosts occupy (Wootton, 1998; Helfman et al. 2009). The reproductive 181 diversity of teleosts may, therefore, simply reflect the reproductive adaptations that are 182 required for them to occupy this range of habitats. However, species richness alone is an unsatisfactory explanation for their

184 reproductive diversity, since it still begs the question of why the teleosts have speciated 185 to such a spectacular degree in comparison with other vertebrates. Indeed, this 186 speciosity may be a potent manifestation of underlying mechanisms that have likewise

187 driven the diversification of reproductive modes. Thus there are distinctive 188 characteristics of the teleosts that may have facilitated the evolution of their 189 reproductive diversity.

\section{Whole genome duplication}

191 A key feature of the evolution of the teleosts is that in the early Devonian, after their 192 divergence from the Sarcoptergygii (lobe-finned fishes), and early in the evolutionary 193 history of the teleost lineage, there was a whole genome duplication (WGD) (Amores et 194 al. 1998; Finn and Kristoffersen 2007; Santini et al. 2009), which resulted in each gene 195 being duplicated. Genome duplication presents the opportunity for one of the replicated 196 genes to acquire a new function, termed 'neo-functionalism'. WGD may help to account 
197 for the extraordinary species diversity of teleosts, as well as some of their unusual traits

198 compared with other lineages of jawed vertebrates, by making available a reservoir of 199 genetic variation with the possibility of duplicated genes evolving separate functions 200 and hence opening up the possibility of diversity in reproductive modes (Meyer and 201 Schartl 1999; Le Comber and Smith 2004). Within the teleosts, extremely quick genomic 202 evolution has occurred, with rapid duplication of genes and genomes (Desjardins and 203 Fernald 2009; Mank and Avise 2009), strongly implying that genetic variation leads to 204 reproductive diversity.

205 An example of the impact of WGD is in the evolution of pelagic eggs. The ancestral 206 spawning habit of teleost fishes is benthic eggs. Pelagic eggs need hydration to float and 207 this state is primarily achieved in teleosts through the presence of high concentrations 208 of free amino acids (FAA), which increase the osmolality of the ooplasm resulting in 209 water uptake. During oogenesis, FAAs in the oocyte are derived from the proteolysis of 210 vitellogenin, which is the main source of the proteins and lipids needed by the

211 developing embryo and which is synthesised in the liver of a female before transport to 212 the ovary in the blood supply (Wootton and Smith 2015). The evolution of an effective 213 means of hydrating the oocyte was essential for the teleosts to invade the open ocean, 214 because there are no surfaces on which eggs can be deposited, so the eggs have to be 215 pelagic. Duplication of a vitellogenin gene through WGD appears have allowed the 216 specialisation of a vitellogenin whose neo-function is to be proteolysed to FAA (Finn and 217 Kristoffersen 2007), thereby permitting spawning in open water and invasion of the 218 pelagic environment.

\section{Gonad differentiation}

220 The mode of differentiation of the gonads in teleosts differs from the majority of 221 vertebrates. The gonads of vertebrates have two cellular components; the somatic cells 
222 and the germ cells. It is the latter that give rise to the gametes. In most lineages of jawed

223 vertebrates, the somatic cells have two embryological origins. One population originates

224 from the cells of the walls of the peritoneum, lining the coelomic cavity. This population

225 forms the cortex of the developing gonad. The second population, which forms the

226 medulla of the gonad, is derived from mesonephric blastema, a feature of the developing

227 kidney. In females, the medulla component of the gonad degenerates, while the cortical

228 component expands and gives rise to the ovaries. In males, the development of the testes

229 involves the medulla, while the cortex degenerates (Atz 1964; Merchant-Larios 1978;

230 Nakamura et al. 1998). In terms of the embryological tissues involved, the cortex has a

231 mesodermal origin, while the medulla has an endodermal origin (Francis 1992). It has

232 been argued that the position of cells, cortical or medullary, determines whether they

233 develop as cells characteristic of males or females, though recent evidence from studies

234 on the mouse suggest that the outcome is determined by each cell rather than by the 235 position of the cells (Maatouk and Capel 2008).

236 In teleosts, the gonadal somatic cells are derived only from the peritoneal cells;

237 both ovaries and testes develop from the gonadal cortex and hence have a mesodermal 238 origin. Thus the somatic tissues of the ovaries and testes of teleosts have a common 239 embryological origin (Nakamura et al. 1998). There is a correlation between this 240 distinctive mode of development of the gonads in teleosts and the relative sensitivity of 241 the developing gonad to factors that cause changes in sex of the differentiating gonad, 242 for example the presence of exogenous hormones (Francis 1992). The evidence suggests 243 that teleosts tend to show a protogynous pattern of sexual development, even in 244 gonochorists (Francis 1992). In some teleostean lineages, males pass through a stage in 245 which the gonad develops as a proto-ovary, before switching to differentiate as testis. 246 The position of the cells in the gonadal anlagen is not a factor in their pattern of 247 differentiation. A consequence is that in many teleost species the gonads remain 
248 bipotential until later in development than in other vertebrates. An outcome is that the

249 developmental 'decision' to become a functional male or a functional female is delayed 250 and remains plastic (Adkins-Regan 2005).

251 Allied to this gonadal bipotentiality, teleosts tend to retain a sexually bipotential 252 brain. There is evidence that the sexual behavioural dimorphism seen in teleosts is a 253 consequence of the activational effects of hormones rather than the structural 254 organisation of the brain (Adkins-Regan 2005). A further possible factor is that in 255 teleosts there is adult neurogenesis, which may make flexibility in reproductive 256 behaviour more possible (Adkins-Regan 2005).

\section{Relationship between brain and pituitary}

258 In vertebrates, the brain does not communicate directly with the gonads to control 259 reproduction. Instead, neurohormones produced in the brain, especially the 260 hypothalamus affect the pituitary, the major endocrine organ in vertebrates. Under the 261 influence of these neurohormones, some pituitary cells produce hormones, which are 262 secreted into the blood stream to be transported to the target organs. In the case of the 263 reproductive system, the gonads are the targets. This arrangement is called the brain264 pituitary-gonad reproductive axis (BPG axis), or, to emphasise the role of the 265 hypothalamus of the brain, the HPG axis (Meccariello et al. 2014). In the ovary, the 266 thecal and granulosa cells of the ovarian follicle complex are the target cells. In the

267 testes, the Leydig and Sertoli cells are the main target cells (Wootton and Smith 2015).

268 Modulation and modification of the activity of the BPG reproductive axis can take place 269 at a variety of levels in the axis, including the brain, the pituitary and the gonads (van 270 der Kraak et al. 1998).

271 In comparison with the other jawed vertebrates, the teleosts have an 272 idiosyncratic organisation of the brain-pituitary relationship (Zohar et al. 2010; Kah and 
273 Dafour 2011). In teleosts, hypophysiotropic neurons from the brain pass into the

274 pituitary and release their neurohormones close to the pituitary cells (gonadotropes)

275 that synthesise the hormones (Sherwood and Adams 2005; Levavi-Sivan et al. 2010). In

276 other jawed vertebrates, in contrast, the neurohormones are released into the blood

277 stream and pass into the pituitary in a hypophysial portal system. The adaptive 278 significance of the difference between teleosts and other vertebrates is unclear, but the

279 direct neural connection in teleosts probably allows a faster and more precise control 280 over the secretion of pituitary hormones. Another endocrinological difference is that 281 teleosts produce a non-aromatisable androgen, 11 ketotestosterone (11-KT), which 282 characterises the male and is particularly important in the regulation of male 283 reproductive behaviour (Adkins-Regan 2005; Munakata and Kobayashi 2010).

\section{Conclusions}

285 The unusual reproductive diversity of the teleosts demands explanation. In this brief 286 review three features of the teleosts are proposed as contributing to this diversity (Fig. 287 1). Whole genome duplication generates a pool of duplicated genes that can evolve new 288 functions. The outcome is an enhanced capacity for rapid genomic evolution, potentially 289 encompassing a broad range of reproductive roles. While the functional significance of 290 the idiosyncratic organisation of the brain-pituitary relationship in teleosts has yet to be 291 fully appreciated, it appears to permit a finely-tuned system for controlling pituitary 292 hormone secretion. The outcome is a highly adaptable neuroendorine system that is 293 responsive to social and environmental factors, which may permit the evolution of 294 reproductive tactics unavailable to other jawed vertebrates. The mode of gonad 295 differentiation in teleosts, with gonadal somatic cells in males and females having a 296 common mesodermal origin, generates an inherently protogynous pattern of sexual 297 development, irrespective of mode of sex determination. An outcome of this 
298 bipotentiality is the unusual frequency of hermaphroditism in teleosts, a reproductive 299 strategy rarely expressed in other vertebrates. This lability of the gonads may also 300 facilitate the evolution of multiple alternative mating tactics within species. While these distinctive characteristics of teleost reproduction have been dealt

302 with separately, the interactions of these features may be the key to teleost reproductive 303 diversity. For example, whole genome duplication may be pivotal in facilitating how 304 rapidly the neuroendocrine system is able to respond to selection in generating 305 variation in reproductive patterns. Similarly, the bipotentiality of the teleost gonads and 306 brain may make regulatory mechanisms in the neuroendocrine system more responsive 307 to selection for flexibility in mating behaviour.

308 How might an understanding of these distinctive features of teleost biology be 309 used to explain why the teleosts among all other vertebrates have evolved such an 310 extraordinary diversity of reproduction? Two inter-related explanatory frameworks 311 offer a means to tackle the question: phylogenetic relationships and adaption by natural 312 selection. Phylogenetic lineages map the evolutionary relationships among species and 313 hence map the changes in the gene pool represented by the lineage. This means that the 314 adaptive responses by a population to its physical and social environment are likely to 315 be constrained to a lesser or greater extent by its genetic inheritance (Wootton and 316 Smith 2015). Within these constraints the suite of traits expressed by an individual that 317 determine how it spreads its reproduction over its lifetime is summarised by its life318 history strategy. Life-history theory predicts that selection will favour a pattern of 319 allocation of resources to reproduction over the lifetime of an individual that will 320 maximise the contribution of offspring to the next generation (Roff 1992; Stearns 1992).

321 The challenge is to develop a coherent hypothesis of how the distinctive features of 322 teleost reproduction identified here, and perhaps others yet to be recognized, can 323 explain the diversity of reproductive modes. This will be achieved by using emerging 
324 phylogenetic information about the relationships within the teleost lineage, as well as

325 the large and disparate literature on the reproductive biology of teleosts, interpreted in 326 the context of life-history theory.

\section{Acknowledgements}

328 The ideas expressed here are the result of a long and productive collaboration with the

329 late Bob Wootton. I am deeply indebted to Paul Hart and Tony Pitcher for encouraging 330 the submission of this review and for the support and kindness I have received from 331 them over my career. Their contributions to the field of fish behaviour and ecology are 332 outstanding. I am also grateful to two anonymous reviewers for their thoughtful and 333 sympathetic comments on an earlier draft of this manuscript.

\section{References}

335 Adkins-Regan, E. (2005) Hormones and Animal Social Behavior. Princeton University 336 Press, Princeton, 416 pp.

337 Amores, A., Force, A., Yan, Y.-L., Joly, L., Amemiya, C., Fritz, A., Ho, R.K., Langeland, L., 338 Prince, V., Wang, Y.-L., Westerfield, M., Ekker, M. and Postlethwait, J.H. (1998) 339 Zebrafish Hox clusters and vertebrate genome evolution. Science 282, 711-714.

340 Atz, J. (1964) Intersexuality in fishes. In: Intersexuality in Vertebrates Including Man (eds 341 C.N. Armstrong and A.J. Marshall), Academic Press, London, pp. 145-232.

342 Avise, J.C. and Mank, J.E. (2009) Evolutionary perspectives on hermaphroditism in 343 fishes. Sexual Development 3, 152-163.

344 Desjardins, J.K. and Fernald, R.D. (2009) Fish sex: why so diverse. Current Opinion in $345 \quad$ Neurobiology 19, 648-653.

346 Erisman, B.E., Petersen, C.W., Hastings, P.A. and Warner, R.R. (2013) Phylogenetic 347 perspectives on the evolution of functional hermaphroditism in teleost fishes. $348 \quad$ Integrative and Comparative Biology 53, 736-754. 
349 Finn, R.N. and Kristoffersen, B.A. (2007) Vertebrate vitellogenin gene duplication in 350 relation to the "3R hypothesis": correlation to the pelagic egg and the oceanic $351 \quad$ radiation of teleosts. PLoS One 2 , e169.

352 Francis, R.C. (1992) Sexual lability in teleosts: developmental factors. Quarterly Review 353 of Biology 67, 1-18.

354 Fryer, G. and Iles, T.D. (1972) The Cichlid Fishes of the Great Lakes of Africa. Oliver and 355 Boyd, Edinburgh, 641 pp.

Helfman, G.S., Collette, B.B. and Facey, D.E. (2009) The Diversity of Fishes, $2^{\text {nd }}$ ed. Wiley357 Blackwell, Oxford, 736 pp.

Kah, O. and Dufour, S. (2011) Conserved and divergent features of reproductive endocrinology of teleost fishes. In: Hormones and Reproduction of Vertebrates, Volume 1 - Fishes (eds D.O. Norris and K.H. Lopez). Academic Press, London, pp. 15-42.

Kolm, N. (2009) Parental care. In: Reproductive Biology and Phylogeny of Fishes (Agnathans and Bony Fishes) (ed. B.G.M. Jamieson). Science Publishers, Enfield (NH), pp. 351-370.

Kraak, G. van der, Chang, J.P. and Janz, D.M. (1998) Reproduction. In: The Physiology of Fishes, $2^{\text {nd }}$ ed. (ed. D.H. Evans, D.H). CRC Press, Boca Raton, pp. 465-488.

Lampert, K.P. and Schartl, M. (2008) The origin and evolution of a unisexual hybrid: Poecilia formosa. Philosophical Transactions of the Royal Society London, B 363, 2901-2909.

Le Comber, S.C. and Smith, C. (2004) Polyploidy in fishes. Biological Journal of the Linnean Society 82, 25-33.

371 Levavi-Sivan, B., Bogard, J., Mananos, E.L., Gomez, A. and Lareyre, J.J. (2010) Perspectives on fish gonadotropins and their receptors. General and Comparative Endocrinology 
374 Maatouk, D.M. and Capel, B. (2008) Sexual development of the soma in the mouse.

375 Current Topics in Developmental Biology 83, 151-183.

376 Mank, J.E. and Avise, J.C. (2009) Evolutionary diversity and turn-over of sex 377 determination in teleost fishes. Sexual Development 3, 60-67.

378 Mank, J.E., Promislow, D.E.L. and Avise, J.C. (2005) Phylogenetic perspectives in the 379 evolution of parental care in ray-finned fishes. Evolution 59, 1570-1578.

380 Meccariello, R., Fasano, S., Pierantoni, R. and Cobellis, G. (2014) Modulators of 381 hypothalamic-pituitary-gonadal axis for the control of spermatogenesis and sperm 382 quality in vertebrates. Frontiers in Endocrinology 5, 135.

383 Merchant-Larios, H.C. (1978) Ovarian differentiation. In: The Vertebrate Ovary (ed. R.E. 384 Jones). Plenum Press, London, pp. 47-81.

385 Meyer, A. and Schartl, M. (1999) Genes and genome duplications in vertebrates: the one386 to-four (-to-eight in fish) rule and the evolution of novel gene functions. Current 387 Opinion in Cell Biology 11, 699-704.

388 Munakata, A. and Kobayashi, M. (2010) Endocrine control of sexual behaviour in teleost 389 fish. General and Comparative Endocrinology 165, 456-468.

390 Nakamura, M., Kobayashi, T., Chang, X-T. and Nagahama, Y. (1998) Gonadal sex 391 differentiation in teleost fish. Journal of Experimental Zoology 281, 362-372.

392 Neaves, W.B. and Baumann, P. (2011) Unisexual reproduction among vertebrates. 393 Trends in Genetics 27, 81-88.

394 Pandian, T.J. (2011).Sexuality in Fishes. CRC Press, Boca Raton, 208 pp.

395 Patzner, R.A. (2008) Reproductive strategies in fish. In: Fish Reproduction (eds M.J. 396 Roche, A. Arukwe and B.G. Kapoor). Science Publishers, Enfield (NH), pp. 311-350.

397 Roff, D.A. (1992) The Evolution of Life Histories. Chapman and Hall, London, 548 pp. 
398 Santini, F., Harmon, L.J., Carnevale, G. and Alfaro, M.E. (2009) Did genome duplication 399 drive the origin of teleosts? A comparative study of diversification in ray-finned $400 \quad$ fishes. BMC Evolutionary Biology 9, 194.

401 Patzner, R.A. (2008) Reproductive strategies in fish. In: Fish Reproduction (eds M.J. 402 Roche, A. Arukwe and B.G. Kapoor). Science Publishers, Enfield (NH), pp. 311-350.

403 Sherwood, N.M. and Adams, B.A. (2005) Gonadotropin-releasing hormone in fish: 404 evolution, expression and regulation of the GnRH gene. In: Hormones and their 405 Receptors in Fish Reproduction (eds P. Melamed and N. Sherwood). World Scientific, $406 \quad$ New Jersey, pp. 1-39.

407 Smith, C. and Wootton, R.J. (1995) The costs of parental care in teleost fishes. Reviews in $408 \quad$ Fish Biology and Fisheries 5, 7-22.

Stearns, S.C. (1992). The Evolution of Life Histories. Oxford University Press, Oxford, 264 410 pp.

411 Taborsky, M. (2008). Alternative reproductive tactics in fish. In: Alternative Reproductive 412 Tactics (eds R.F. Oliviera, M. Taborsky and H. Brockmann). Cambridge University 413 Press, Cambridge, pp. 251-299.

414 Tatarenkov, A., Earley, R.L., Taylor, D.S. and Avise, J.C. (2012) Microevolutionary 415 distribution of isogenicity in a self-fertilizing fish (Kryptolebias marmoratus) in the 416 Florida keys. Integrative and Comparative Biology 52, 743-752.

417 Wong, M. and Balshine, S. (2011) The evolution of cooperative breeding in the African 418 cichlid fish, Neolamprologus pulcher. Biological Reviews 86, 511-530.

419 Wootton, R.J. (1998) Ecology of Teleost Fishes, $2^{\text {nd }}$ ed. Elsevier, Dordrecht, 386 pp.

420 Wootton, R.J. and Smith, C (2015) Reproductive Biology of Teleost Fishes. Wiley$421 \quad$ Blackwell, Oxford, $496 \mathrm{pp}$. 
422 Wourms, J.P. (1981) Viviparity: the maternal foetal relationship in fishes. American $423 \quad$ Zoologist 21, 473-575.

424 Zohar, Y., Muñoz-Cuerto, J.A., Elizur, A. and Kah, O. (2010) Neuroendocrinology of 425 reproduction in teleost fish. General and Comparative Endocrinology 165, 438-455. 426 


\section{Figure caption}

427 Figure 1 Distinctive features of teleost reproduction, their functional significance and 428 the potential evolutionary outcomes for reproductive diversity. Arrows indicate 429 proposed impacts.

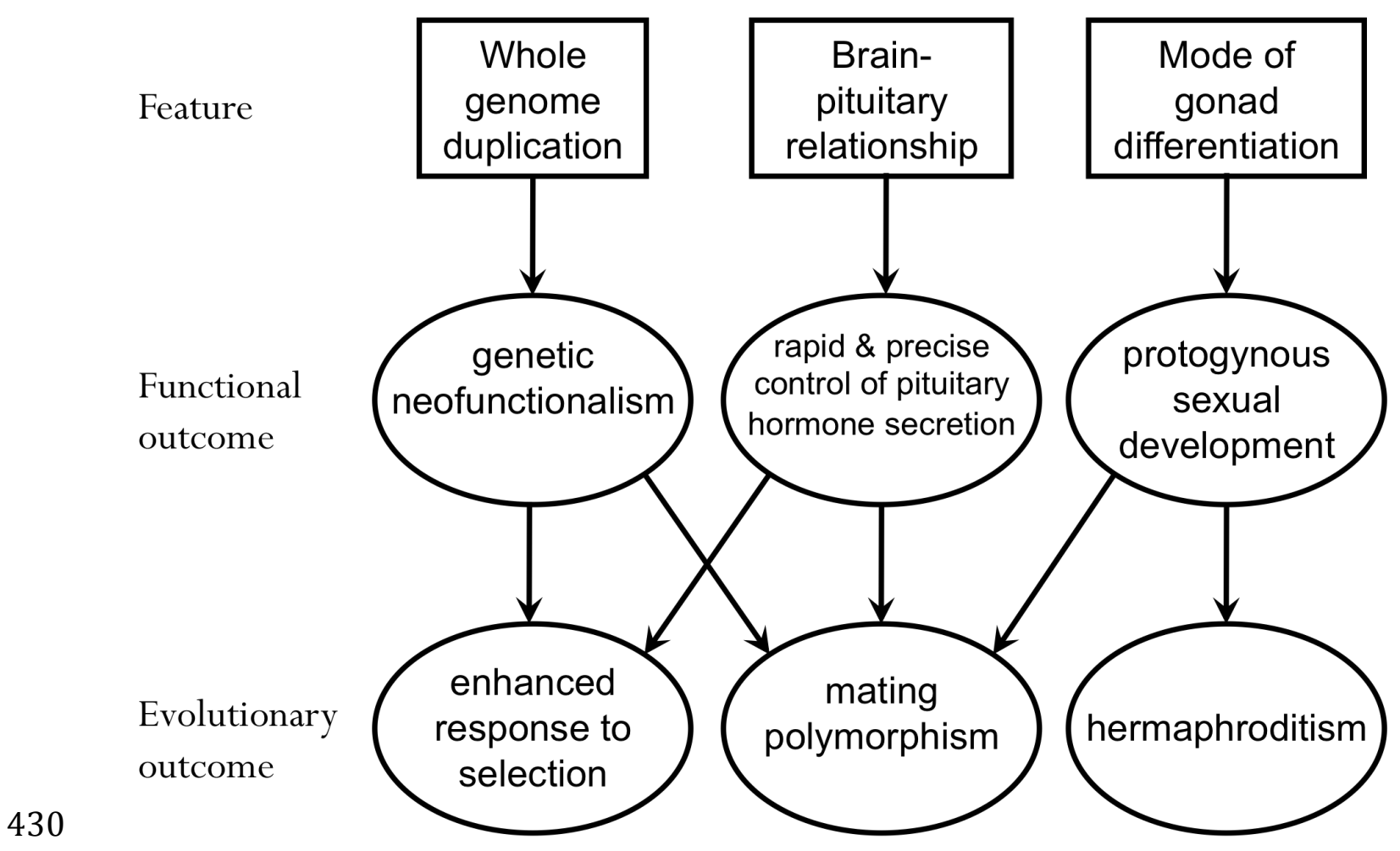

